2 Wheeldon NM, MacDonald TM, Flucker CJ, McKendrick AD, McDevitt DG, Struthers AD. Echocardiography in chronic heart failure in the community. Quart J Med 1993;86:17-23.

3 McMurray J, Hart W, Rhodes G. An evaluation of the economic cost of heart failure to the National Health Service in the United Kingdom. $\mathrm{BrJ}$ Med Econ 1993;6:99-110.

4 Remes J, Miettinen H, Reunanen A, Pyorala K. Validity of clinical diagnosis of heart failure in primary health care. Eur Heart J 1991;12:315-21.

5 Murphy JJ, Frain JP, Ramesh P, Siddiqui RN, Bossingham CM. Open-access echocardiography to general practitioners for suspected heart failure. BrJ Gen Pract 1996;46:475-6.

6 Clarke K, Gray D, Hampton JR. Evidence of inadequate investigation and treatment of patients with heart failure. Br Heart J 1994;71:584-7.

7 Horne R, Coombes I, Davies G, Hankins M, Vincent R, et al. Barriers to optimum management of heart failure by general practitioners. Br J Gen Pract 1999:49:353-7.

8 Hobbs FD, Jones MI, Allan TF, Wilson S, Tobias R. European survey of primary care physician perceptions on heart failure diagnosis and management (Euro-HF). Eur Heart J 2000;21:1877-87.

9 Houghton AR, Cowley AJ. Why are ACE inhibitors underutilized in the treatment of heart failure by general practitioners? Int J Cardiol 1997;59:7-10

10 Hobbs FD. Management of heart failure: evidence versus practice. Does current prescribing provide optimal treatment for heart failure patient? Br J Gen Pract 2000;50:735-42.

11 Patton MQ. Qualitative evaluation and research methods. 2nd ed. London: Sage, 1990 .

12 Melia K. Producing "plausible stories": interviewing student nurses. In: Miller G, Dingwall R, eds. Context and method in qualitative research. London: Sage, 1997:26-36.

13 Glasser BG, Strauss AL. The discovery of grounded theory: strategies for qualitative research. Chicago: Aldine, 1967.

14 Bloor M. Techniques of validation in qualitative research: a critical commentary. In: Miller G, Dingwall R, eds. Context and method in qualitative research. London: Sage, 1997:37-50.

15 Task Force of the Working Group on Heart Failure of the European Society of Cardiology. Guidelines for the treatment of heart failure. Eur Heart J 1997;18:736-53

16 Cleland JGF, McGowan J, Clark A. The evidence for $\beta$ blockers in heart failure. BMJ 1999;824-5.

17 Rimington H, Adam G, Chambers J. Open-access echocardiography. Lancet 1996;348:555-6.

18 Freeman AC, Sweeney K. Why general practitioners do not implement evidence: qualitative study. BMJ 2001;323:1100-2.

19 Department of Health. The national service framework for coronary heart disease. London: Stationery Office, 2000

(Accepted 4 November 2002)

\title{
Identifying depression in primary care: a comparison of different methods in a prospective cohort study
}

\author{
Verena Henkel, Roland Mergl, Ralf Kohnen, Wolfgang Maier, Hans-Jürgen Möller, Ulrich Hegerl
}

Department of

Psychiatry, LudwigMaximilians-

University Munich,

Nußbaumstr 7

D-80336 Munich,

Germany

Verena Henkel

psychiatrist

Roland Mergl

psychologist

Hans-Jürgen Möller

professor

Ulrich Hegerl

professor

Institute for Medical

Research

Management and

Biometrics

(IMEREM),

Scheurlstr 21,

D-90478

Nuremberg,

Germany

Ralf Kohnen

professor

Department of

Psychiatry,

University of Bonn,

Sigmund-Freud-Str

25, D-53105 Bonn,

Germany

Wolfgang Maier

professor

Correspondence to:

V Henkel

verena.henkel@

psy.med.

uni-muenchen.de

BMJ 2003;326:200-1
Depressive disorders are a major health problem in primary care, and at least half of these disorders remain undetected. ${ }^{1}$ There are two recommended approaches to diagnosing depression in primary care: one is to perform routine screening, and the other is to evaluate patients only when the clinical presentation triggers the suspicion of depression. Our aim was to compare these two approaches, and to compare three different screening tools in order to evaluate which would be most appropriate for use in primary care. From among the many available screening tools, we selected three brief, self rating instruments: one disorder-specific (the depression module of the brief patient health questionnaire (B-PHQ 9 items)), ${ }^{2}$ one broad based (the general health questionnaire (GHQ-12, 12 items)), ${ }^{3}$ and one that is less restricted to both issues (WHO-5 wellbeing index (WHO-5, 5 items)). ${ }^{4}$

\section{Methods and results}

Eighteen primary care facilities participated in our prospective cohort study. The study protocol was approved by our local ethics committee. On one given day, all patients who presented in one of the practices were asked to complete the three screening questionnaires before seeing a doctor. The doctors who treated the patients remained blind to the questionnaire results until they had completed a brief "physician's encounter form" to indicate their clinical assessment of their patient's current diagnoses.

Within a period not exceeding six days after they had completed the questionnaires, the patients were contacted by telephone for a fully structured, standardised psychiatric interview (composite international diagnostic interview (CIDI)) conducted by a trained psychologist blind to the screening results. We chose the composite international diagnostic interview as the reference standard because its reliability and validity have been established. ${ }^{5}$ The interviewing psychologists met a high standard of inter-rater reliability.

The main outcome measures were, firstly, the family doctors' performance in detecting depression without any tool to help guide diagnosis decisions and, secondly, the test accuracy of the screening questionnaires. We calculated sensitivity, specificity, and predictive values using two-by-two tables. We used two statistical tests to compare differences of characteristics of test accuracy (table).

For 431 patients, all screening questionnaires, the composite international diagnostic interview, and the physician's encounter form were completed. Of these patients, $17 \%$ suffered from any depressive disorder and $83 \%$ did not.

\section{Comment}

The sensitivity of the family doctors' unaided clinical diagnoses was $65 \%$. With standard cut-off points, the briefest screening questionnaire (and therefore the most practical to use), the WHO-5, produced significantly greater sensitivity $(93 \%)$ and a better negative predictive value $(98 \%)$ than the other questionnaires (see table). However, the brief patient health questionnaire and unaided clinical diagnosis produced better specificity. The brief patient health questionnaire also produced the best positive predictive value. However, since screening tools are designed to identify all patients at risk for a disorder, sensitivity and negative predictive value are the most important operating characteristics. 
Comparison of test accuracy of screening questionnaires for depression and family doctors' unaided clinical diagnosis. Values are means $(95 \%$ confidence intervals) unless stated otherwise

\begin{tabular}{|c|c|c|c|c|c|}
\hline \multirow[b]{2}{*}{ Measures of test accuracy } & \multicolumn{3}{|c|}{ Screening questionnaires } & \multirow{2}{*}{$\begin{array}{l}\text { Unaided clinical } \\
\text { diagnosis (UCD) }\end{array}$} & \multirow{2}{*}{$\begin{array}{c}\text { Significant differences }(P \leq 0.05 \\
\text { one sided tests)§ }\end{array}$} \\
\hline & WHO-5* & GHQ-12† & B-PHQ‡ & & \\
\hline Sensitivity (\%) & 93 (85 to 98$)$ & 85 (74 to 92$)$ & 78 (66 to 87$)$ & 65 (53 to 76$)$ & WHO-5>GHQ-12, B-PHQ>UCD \\
\hline Negative predictive value (\%) & 98 (95 to 99$)$ & 95 (92 to 98$)$ & 95 (92 to 97$)$ & 91 (88 to 94$)$ & $\begin{array}{c}\text { WHO-5>B-PHQ>UCD, } \\
\text { GHQ-12>UCD }\end{array}$ \\
\hline Specificity (\%) & 64 (59 to 69) & 62 (57 to 67$)$ & 85 (81 to 89$)$ & 74 (69 to 79$)$ & $\begin{aligned} \mathrm{B}-\mathrm{PHQ} & >\mathrm{UCD}>\mathrm{WHO}-5, \\
\mathrm{UCD} & >\mathrm{GHQ}-12\end{aligned}$ \\
\hline Positive predictive value (\%) & 34 (28 to 41$)$ & 31 (25 to 38$)$ & 51 (42 to 61 ) & 34 (26 to 42$)$ & $\begin{array}{c}\text { B-PHQ }>\text { WHO- } 5>G H Q-12, \\
\text { B-PHQ }>U C D\end{array}$ \\
\hline
\end{tabular}

*WHO-5 wellbeing index (scoring procedure as indicated in World Health Organization info package ${ }^{4}$ ).

$\dagger$ General health questionnaire (scoring procedure as indicated in Goldberg 1978 ${ }^{3}$ ).

łBrief patient health questionnaire (scoring procedure as indicated in Spitzer et al $1999^{2}$ ).

$\S M c N e m a r$ 's test to compare sensitivities and specificities, analogue of McNemar's test to compare predictive values.

Our results suggest that the use of WHO-5 could improve family doctors' ability to detect depression, supporting the World Health Organization's recommendation that every patient in primary care should participate in a screening process with the completion of WHO-5 as a standard first step, done in the waiting room. ${ }^{4}$ The questionnaire can easily be scored by hand. Patients who score positively for depression should be examined by their doctor in order to confirm a diagnosis of depression or to rule out normal distress or physical causes of depression. At this stage, doctors could use the brief patient health questionnaire as a checklist.

We hope that our results favouring such a simple, two stage screening process for depression in primary care, starting with the questionnaire $\mathrm{WHO}-5$, will encourage further research in other countries.

We thank Simone Braun, Kathrin Allgaier, Petra Ohlendorf, Isabelle Seidscheck, and Evelyn Poth for data collection. We thank Jan Stefanek and Simone Braun for conducting the ROC-analyses presented in an earlier draft of this paper.

Contributors: VH had the idea for this paper and drafted the paper. RM analysed the data. RK, WM, H-JM, and
UH commented on the study protocol and the text of the paper. UH is the speaker of the "German Research Network on Depression." VH and UH are guarantors for the study.

Funding: The study was funded by grants from the German Federal Research Ministry within the programme "German Research Network on Depression" and by additional funds from Pfizer and Novartis.

Competing interests: None declared.

1 Paykel ES, Tylee A, Wright A, Priest RG, Rix S, Hart D. The defeat depression campaign: psychiatry in the public arena. Am J Psychiatry 1997;154(6 suppl):59-65.

2 Spitzer RL, Kroenke K, Williams JB. Validation and utility of a self-report version of PRIME-MD: the PHQ primary care study. Primary care evaluation of mental disorders. Patient health questionnaire. JAMA 1999;282:1737-44

3 Goldberg DG. Manual of the general health questionnaire. Windsor: NFER Publishing, 1978.

4 World Health Organization info package:Mastering depression in primary care. Frederiksborg: World Health Organization, Regional Office for Europe, Psychiatric Research Unit, 1998.

5 Andrews G, Peters L. The psychometric properties of the composite international diagnostic interview. Soc Psychiatry Psychiatr Epidemiol 1998;33:80-8.

(Accepted 15 August 2002)

\section{One hundred years ago}

\section{Anaesthesia and swearing}

Our armies, as we learn from My Uncle Toby, swore terribly in Flanders; and if the testimony of Mr. Kipling is to be accepted they do the same at the present day in India and elsewhere. In civil life the strong language of our ancestors has to a large extent been replaced by meaningless slang. It would have been impossible to damn every one and everything more comprehensively or more consistently than Lord Melbourne, the political mentor of our late gracious sovereign, Queen Victoria. Fifty or sixty years ago surgeons, like other folk, swore freely; and if they are now less full of strange oaths, that is due partly to what Matthew Arnold called the stream of tendency and partly to a wider diffusion of training in the liberal arts which has softened the ferocity of our manners. In the Hunterian Oration delivered the other day Sir Henry Howse expressed the opinion that the disuse of profane language among surgeons might be regarded as one of the blessings of chloroform. Anaesthesia, according to the President of the Royal College of Surgeons of England removed "the necessity for the surgeon to express himself in such forcible and inelegant terms as was necessary previously for the control of his patient." We venture to think that this theory is unfair to the surgeons of pre-anaesthetic times. Men are apt to use strong language when they are strongly moved, and in the old days many surgeons may have sworn during operations, as boys whistle in going through a graveyard at night, to give themselves courage. We know what men like Cheselden, Charles Bell, and Astley Cooper suffered when they had to undertake a serious operation, and how they had to nerve themselves for the task. In the old days surgeons as a class unquestionably were rougher in manner and language than they are nowadays, but that is because only men of blood and iron could have practised the art of chirurgery under the conditions then existing. We decline to believe, however, that our predecessors were brutal enough to swear at the patients who were shrieking under the knife, and we cannot admit that the introduction of anaesthesia removed "the necessity for strong speech and roughness of manner in the veterans who have gone before us."

(BMJ 1903;i:452) 